\title{
Sir David Bruce Memorial Lecture 1988
}

\section{C Morrell, OBE KSG FRCP FRCGP}

Dept of General Practice United Medical and Dental Schools, Guy's and St Thomas' Hospitals, London

I should like to begin by saying how much I appreciate the honour of being asked to give this lecture and also to say how much this has contributed to my own education. I have spent many enjoyable hours among the dusty tomes of British Medical Journals and Lancets from the turn of the century reading some of Sir David's 170 published papers. From this and from reading some of the biographies of his life, I have tried to get a feel for the man who contributed so much to epidemiology in the early part of this century.

He was born in Melbourne, Australia in 1855, but came to this country to live in Stirling at the age of five years. His father had emigrated to Australia at the time of the gold rush and was clearly a man of considerable drive, courage and ambition. It would seem likely that David Bruce inherited many of his genes, but this was not apparent in his early life. He left school at the age of fourteen and spent some time in business. He then entered Edinburgh University at the age of 21 in 1876 to study zoology. It is apparent that at this time his main interests were in the things of nature and that he was not suited to life in commerce. While at University, he was persuaded by a fellow student to transfer from zoology to medicine and he qualified in 1881.

This was a time of great development in medical science, particularly in the field of microbiology when Pasteur, Koch and Lister were revolutionizing the approach to infection. At first David Bruce appears to have ignored them and he entered general practice in Reigate in 1881 . His biographers quote a number of reasons why he left general practice in favour of the army in 1883 , but the general concensus is that the army offered better money and a more secure future. It is not clear from his biographers how much he contributed to general practice during his two years in Reigate. What is however very clear is that general practice contributed very greatly to his future career by introducing him to Mary Elizabeth Steel, the daughter of a general practitioner in Reigate. He subsequently married her and she played a major part in the work he was later to undertake in the field of epidemiology.

There is no doubt that at an early stage the army recognised his potential and his posting to Malta where undulant fever was presenting major problems was more than fortuitous. He very quickly identified the organism responsible for Malta fever although it was some years later, in 1905, that he linked this to its transmission in goats milk. This was perhaps the most important discovery of his career because it identified the role of the symptomless carrier in the transmission of disease and was coincident with the same discoveries by Koch and his co-workers on the importance of symptomless $\underset{\overrightarrow{0}}{\overrightarrow{0}}$ carriers in the transmission of typhoid fever.

His work on Nlagana in Zululand was another $\frac{2}{\circ}$ highlight of his career. His posting to South Africa was $\frac{\bar{\sigma}}{\bar{\omega}}$ engineered by the late Governor General of Malta, $\frac{\vec{\sigma}}{\vec{\sigma}}$

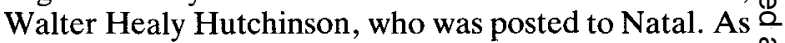
the new Governor of Natal, he was faced with an is economically disastrous outbreak of nagana in that area $\overrightarrow{0}$ and asked for Bruce to be seconded to investigate this problem. One might be tempted to say that this is an $\vec{\omega}$ example of the importance of who you know, rather? than what you know, in determining your posting. This would however be very unfair in this context, because in the years between Malta and Zululand, Bruce had spent $\vec{\omega}$ some time in Koch's laboratories learning the most up- ô to-date techniques, and several years as assistant professor of pathology at Netley. His work in Zululand $\hat{N}^{\circ}$ did unleash his enormous potential and living with his 0 wife in primitive conditions, in an almost intolerab望 climate in what was described as the 'fly belt', he mad some of his most important discoveries.

So what sort of man are we talking about. He we undoubtedly athletic of somewhat fearsome physici $\vec{\varnothing}$ proportions. He is variously described by his biographers as picturesque, able, forthright, hard, ster not easy to approach. Many suggest that he preferred frontal attack on any problem presented to him. The is also no doubt that he was supported in the most remarkable way by his wife. There is a lovely story about $\frac{\circ}{\triangleright}$ an occasion when he was Commandant of the Royal $\stackrel{2}{\overrightarrow{7}}$ Army Medical College and he returned rather dejected $\frac{3}{3}$ to his wife following a meeting. She suggested that if he would avoid telling people at the outset what incredible fools he thought they were, he might find that things would work more smoothly. I feel sure that that message has passed down in history to Commandants of this College.

Sir David was concerned throughout his life with man and his environment and how this environment produced the diseases from which men suffered, be they undulant fever in Malta, sleeping sickness in Africa or 3 trench fever in the low countries. His main preoccupation was the way the environment led to infection through a variety of organisms and protozoa $ᄋ$ and how these infections were spread. $\mathrm{He}$ was an epidemiologist in the classical mould and his attention to detail was outstanding. He described, in enormous detail, the appearances and breeding habits of the tsetse $\sigma$ fly, which must have involved him in hours of $N$ painstaking observation, exposure to intolerable heat $\mathcal{W}_{\mathrm{W}}$ and attacks from innumerable insects, and all the time 
his wife was at his side. It is very difficult to imagine the discomforts they must have suffered in Africa while they unravelled the causes of nagana and sleeping sickness.

For many years he worked in the field, in Malta, South Africa and Uganda, but when he came back to base camp at last, during the First World War, his interests in epidemiology continued and he became particularly concerned with the problems presented by tetanus. He was chairman of a committee which produced many reports on tetanus and the value of anti-tetanus serum. As a result of his efforts the mortality rate from tetanus fell dramatically. During this time he notes in one of his reports that Lady Bruce spent five hours per day for three years analysing data from the field and home hospitals. She must have been a very remarkable lady.

In the last half century the concerns of epidemiologists have changed from infectious diseases and their prevention by public health measures, immunization and the use of antibiotics, to other problems. Epidemiologists are now concerned more with the aetiology of chronic disease which is often multifactorial in origin and in some ways more difficult to explore and incidentally far less glamorous.

At the time when Bruce was most active and science was making its most impressive contributions to medicine, medical education was still at a very primitive stage in its development. It was largely entrepreneurial and delivered by specialists working in the teaching hospitals. It was as a result of the important scientific discoveries at the turn of the century that Flexner in 1910 was invited by the Carnegie Foundation to examine medical education in the United States and he later extended these studies to Europe.

$\mathrm{He}$ argued that education at that time was based on empiricism rather than on a scientific foundation. We do not know, but I suspect, that Bruce would have responded very positively to this statement. Flexner indeed had a major impact on medical education and from then on both in the United States and Europe, the pattern of education changed. Some of Flexner's critics contended that he over-emphasised the importance of a scientific base for medical education at the expense of a compassionate approach to the sick and an appreciation of the environment in which they lived. Such criticism was unjustified. Flexner identified the bimodal nature of medical education with both the scientific and compassionate modes. He stated "To be in the interests of patients, medical decisions must be both scientifically correct and morally good. The capacity to observe accurately, to measure and weigh signs, symptoms and laboratory data are essential to competent medicine, but the good clinician who stood back and detached himself from the patient must then re-attach himself to the patient and place his scientific conclusions back into the context of the patient's illness. Only in this way can he determine whether what is proper for a cohort of patients is proper for this patient and whether what is medically effective is also beneficial to the total good of this patient. Compassion and competence are therefore inseparable in the good physician. Attacks on the science of medicine are as ludicrous as attacks on compassion. Competence is essential to compassion; compassion to competence".

John Ryle, an outstanding physician at Guy's and subsequently a Professor of Social Medicine at Oxford, was also fascinated with this problem of marrying science and compassion. In his masterpiece on the natural history of disease, last published in 1947, he wrote "a student is imbued with the importance of experiment and of laboratory methods, and is then asked to contemplate the bewildering problems of man in disease. He does not see enough of disease in the simpler forms and the early stages in the natural environment. At no point is he offered the strong helping hand of a broad medical philosophy. How is he to become more of a naturalist and less of a receptacle for laboratory law or the tenets and teachings of individual professors". I am sure David Bruce would have applauded that statement.

This century, and in particular the last 60 years, has been littered with reports designed to provide solutions to this problem of marrying science and compassion in medical education and teaching about man in his environment, but few have led to major changes in the medical curriculum in our universities.

In 1922, the General Medical Council produced a review of medical education in which it emphasised that "the spirit of preventive medicine should animate all the teachings to students and be illustrated continually in the treatment of cases". It was however, impossible for medical schools to respond because their teachers' skills and the illnesses of their patients were unsuited to such aims. The specialists were unable and did not wish to teach outside their own field and the only people whom they could teach were those in the wards of the hospitals. The resolutions of the GMC produced little change and the GMC fell silent on this subject for 14 years. In 1936, new resolutions regarding the medical curriculum were published by the GMC. These differed little from those in 1922, and the aim of medical education remained the production of a doctor fit to start at once in independent practice, but one who continued to be trained by hospital specialists about clinical problem solving in the hospital setting with little concern for man in his environment or prevention.

Little happened over the war years, but in 1942, following the Beveridge Report which envisaged the development of a National Health Service, an interdepartmental committee, the Goodenough Committee, was appointed to review the provisions for medical education and research, including the facilities and payment of teachers. Goodenough criticised the content of medical education, but believed that a National Health Service would itself alter this, stating that in such a service the "ideas of social medicine must permeate the whole of the medical education". He was however, 
to be disappointed because in 1947 the GMC produced a document entitled "Recommendations on Professional Education" which showed no indication that the new service was having any significant effect on medical education. Teachers of all clinical subjects were to draw the attention of students to the inter-relationship of the physical and psychological aspects of disease. Social medicine was to be taught through the use of Public Health and Welfare facilities.

At about the same time, the BMA Curriculum Committee, chaired by Henry Cohen, was reviewing medical education. It reported in 1948 and in contrast to all previous official writing, it rejected the idea that the purpose of undergraduate education was to produce a competent GP. It remarked that there was a need for radical changes in the curriculum which was founded on disease entities, rather than the patient as a whole. It was suggested that GPs contribute to teaching in order to bring about change. The Committee considered this possibility but rejected it. The reasons for rejecting the proposal are interesting. "There are probably no suitably qualified GPs and patients resent the presence of students in general practice". The upshot of this report was that the BMA set up another committee, also chaired by Henry Cohen, to consider training for general practice. Cohen I, in 1948, rejected general practice as a resource for undergraduate training. Cohen II recommended a three year postgraduate training for general practice, the forerunner of our present vocational training scheme.

It was about this time that I came on the scene. I qualified in 1952 and entered a period as house officer before fulfilling my duties to King and Country in, I have to say, the Junior Service. I entered general practice in 1957. Academically, I was well prepared, being a member of the Royal College of Physicians and Diplomate of the Royal College of Obstetricians and Gynaecologists. I rapidly realised however, I was totally unprepared for the problems I encountered. The Goodenough Committee and the Cohen Committee had stressed the need for general practitioners to have a positive approach to health and disease prevention, and Departments of Social and Preventive Medicine had been developed in Medical Schools to satisfy this need. This appeared to me almost peripheral to the real problems of general practice which I encountered at that time. These were concerned with interpreting symptoms presented in primary care, making clinical decisions at this level of care and developing management strategies. They were concerned with managing illness where no diagnosis could be made and planning the continuing care of patients suffering from chronic disease. They were concerned with understanding the effect of family dynamics and the environment on the aetiology of and response to illness. I remember in my early days the enormous feelings of guilt when I did not examine and investigate all the problems presented to me and when, in response to problems, I could not write down a diagnosis. I might well have descended into the "Slough of Despond," as did many of my contemporaries, had $\mathbf{F}$ not met with a number of doctors who were asking the $?$ same questions as myself and I suppose the most $\stackrel{\mathbb{Q}}{\varrho}$ important of these questions was, "is the method of $\bigcirc$ problem solving we have learned in the teaching hospital 응 relevant to the medical care we are providing, or should ? we, by careful research, identify a more appropriate $\vec{\Rightarrow}$ method?"

I was very fortunate, I had joined the Royal College of General Practitioners in 1957, and was a member of $\frac{\overline{\bar{c}}}{\mathrm{~s}}$ the northern home counties faculty. On the faculty $\vec{\sigma}_{\bar{\phi}}$ board which I shortly joined were, among others, John $\varnothing$ Horder, subsequently President of the College; Basil Slater, later to become Secretary of the College; Paul $\overrightarrow{0}$ Freeling, Marshall Marinker and John Benison. We were all asking the same questions, and during my five $\vec{\omega}$ years in general practice in Hoddesdon, I tried to collect $\stackrel{?}{?}$ information about general practice which would be of value to new entrants to this career. I subsequently? published this in my first book entitled, "The Art of $\frac{\dot{\omega}}{\omega}$ General Practice". In the preface I wrote, "I know that ô after a few years in General Practice, I will be unable to see the difficulties facing a newcomer and I decided to remedy this by making a note of them as they occurred. $\mathrm{N}$ This book is a summary of some of the problems प्र encountered and solutions I have worked out as the years have gone by".

In preparing this lecture, I was fascinated whend pulled this old book out of the book-case and re-rea $\vec{\varphi}$ what I had written 25 years ago because I believe thgt 0 this summarises the purpose of creating Academic Departments of General Practice. They are concerned with advancing knowledge in the field of general practice by research and transmitting this knowledge to the next generation.

After five years of practice in Hoddesdon in $\stackrel{\mathbb{2}}{\Rightarrow}$ Hertfordshire, I was lured by Dick Scott to join him in Edinburgh as a lecturer in his department in 1963. He had great hopes of establishing there the first Chair of General Practice. In 1966, he was appointed the first Professor of General Practice in the world. One year later, I moved back to London as a senior lecturer in general practice at St. Thomas's Hospital Medical School in the Department of Clinical Epidemiology and $\overparen{\mathbb{d}}$ Social Medicine.

This appointment coincided with the report of the Todd Commission, set up by the Government in 1965 to 3 . review medical education. The Todd Report came down very strongly in favour of recognising general practice as a specialty. This, in due course, was interpreted as 0 meaning that general practitioners needed specialty training which fitted in well with the then views of the Royal College of General Practitioners on the need for compulsory vocational training.

At the time, and indeed today, I regard the definition $N$ of general practice as a specialty as detrimental to its development. General practice to me is a method of ${ }_{\sigma}^{\omega}$ 
delivering medical care in the community. In fulfilling this role, it draws on knowledge and skills derived from a variety of disciplines. These include the clinical disciplines, epidemiology, behavioural sciences and medical ethics. Labelling general practice as a specialty in academic terms suggests that it possesses a unique body of knowledge which can be scientifically described. This is not so. What characterises general practice is the way in which it applies knowledge derived from a variety of disciplines to the problems which it encounters. The great strength of general practice in the field of undergraduate education is that it embraces all the specialties but relates them to the problems experienced in the community. It puts them all in perspective. It uses methods of problem solving which draw on knowledge from clinical and behavioural models and produces effective and efficient patient care. It orchestrates the whole medical team, both therapeutic and preventive, in the provision of optimal care for defined populations. As such, it has a unique part to play in the delivery of medical care and medical education.

My appointment at St. Thomas's was supported by a research grant from the DHSS. This grant was for a period of three years. During this time I was charged with "demonstrating the difference between medicine practised in general practice and hospital medicine". Only if I could demonstrate this difference would the Medical School be prepared to countenance teaching in general practice for its undergraduates and finance such an operation. I arrived in London with a wife and five children and we had three years in which to justify our existence. Such a challenge concentrates the mind enormously.

When I came to London, I moved into shop-front surgery premises in partnership with $\mathrm{Dr}$ George Gage in Westminster Bridge Road, a short distance from St. Thomas's and we took on a third partner. We provided care for four and a half thousand patients and it was these patients who were the population we studied. We looked in detail at the care provided for them in hospital and general practice over a period of one year. In this study, we were able not only to demonstrate the relative contributions of primary and secondary care, but also to examine, in some detail, the patterns of symptoms presented and their interpretation at primary care level.

As a result of this work we learned that the symptoms presented in general practice were different from those presented in hospital and the interpretation of these symptoms in terms of diagnostic probabilities was also totally different. We had, at that time, been brought up on knowledge derived from the study of patients presenting in hospital out-patient departments. In general practice we were caring for patients at a much earlier stage in the natural history of disease and a great deal of our knowledge was totally inappropriate in the situation in which we found ourselves. The decision to seek medical care in general practice is a lay decision and differs fundamentally from the decision to seek specialist care which is a professional decision made by the general practitioner. In order to understand the lay decision to seek general practitioner care, it is clearly necessary to study in more detail the factors, very often environmental, which determine why an individual experiencing symptoms of illness decides to seek professional advice. In order to do this we asked a random sample of patients in our practice to keep diaries of their health over a period of four weeks and over a period of one year recorded their requests for professional care in general practice. At the same time we asked them to complete a number of questionnaires designed to measure such variables as anxiety, depression, community support and a number of other social factors.

In this way we were able to demonstrate that only a very small proportion, about 1 in 40 , of the symptoms recorded by individuals in health diaries led to a consultation with a general practitioner, although over 50 per cent led to self medication. We were able to demonstrate the importance of anxiety measured objectively, depression, community support and satisfaction with the community in which they live in determining whether or not individuals experiencing symptoms of illness would consult a doctor. From these studies we were able to demonstrate that the interpretation of symptoms presented in primary care must take into account not only the nature of the symptom presented but the environment and $\stackrel{\mathbb{Q}}{\varrho}$ personality of the individual experiencing this symptom Our research went on to demonstrate that the response to symptoms could be modified by health education in for instance, the management of minor illness education which was designed to reduce anxiety.

I have continued over a period of twenty years to develop research in this field. Some of this research has been concerned with interpreting human behaviour in response to symptoms of illness and recently we have moved into the area of health beliefs and how these differ in different cultures. Other research projects have been concerned with studying the natural history of common problems presented in general practice, such as backache, dysuria, vaginal discharge, and night cough in children. All of these studies have demonstrated a wide divergence between the natural history of diseases depicted in textbooks based on hospital experience and the natural history of disease in the environment in which we work in general practice - the natural environment of men and women in society.

In addition to these studies of the factors influencing demand for medical care and the natural history of the common symptoms presented in general practice, we were able also to study the delivery of medical care. We questioned the development of hospital based antenatal care, which in the 1970 s became a totally depersonalised form of care which lacked all continuity and was repugnant to the patients. We experimented with community based antenatal care in which all the care 
was provided in general practice and the obstetrician consulted in the practice antenatal clinic. In this way we provided continuity and reinstated the specialist as a consultant. Many voices were raised against this take over of antenatal care by general practitioners but we carried out controlled trials to demonstrate its benefits. We did the same for diabetic care with the enthusiastic support of specialists and with excellent results. In the field of prevention we were able to demonstrate that call and recall for immunisations and cervical cytology based in primary care had enormous advantages in terms of acceptance and the facility for audit over nationally based systems.

I have described to you briefly some of the work of one academic department of general practice in demonstrating the knowledge and skills needed by general practitioners to carry out their work and the potential of academic departments to contribute to the education of undergraduates. I could cite many other examples such as the work of the Glasgow Department in geriatric care; of Professor Harris' Department on prescribing: Professor Salkind's Department at Barts into genito-urinary infection and Professor Stott's Department in the field of prevention.

Four years ago, James McCormack from Dublin, John Walker, Paul Freeling and myself reviewed the objectives of undergraduate medical education produced by the General Medical Council and concluded that the achievement of the vast majority of these depended on undergraduates spending a significant proportion of their time in general practice. We summarised this work in an Occasional Paper published by the Journal of the Royal College of General Practitioners. At the same time we were able to identify new areas of knowledge which research in Departments of General Practice have contributed to vocational training.

Despite these efforts, the development of Departments of General Practice has been slow. Two factors have contributed to this in important ways. The first is that in established medical schools it is very difficult to break into the curriculum and it is difficult to compete for funds against powerful departments such as, medicine, surgery and pathology. A more important factor however has been that clinical facilities for undergraduate training in general practice have not been financed as have clinical facilities for teaching in the undergraduate hospitals by a special increment for teaching which ensures adequate staffing to allow for time devoted to teaching. Because general practitioners are independent contractors, the Government has not been legally able under the medical act to acknowledge their contribution to undergraduate education by special payments and the Departments have been inadequately funded to ensure both their own development and the provision of these clinical facilities. There are however clauses in the new White Paper for general practice which may make this type of payment possible and this could revolutionize the contribution which general practice can make to undergraduate medical education, $\frac{z}{3}$ particularly in providing clinical facilities for teaching.

I have mentioned research development and $\bigcirc$ undergraduate teaching in general practice in the $O$ context of the role of academic departments of general

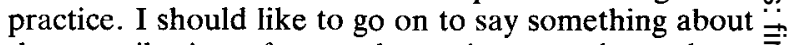
the contribution of general practice to undergraduate $\stackrel{\bar{S}}{\rightarrow}$ education as a whole. I have just retired from Chairmanship of the Education Committee of the $\frac{\bar{\sigma}}{\bar{n}}$ United Medical and Dental Schools of Guy's and St. $\frac{\bar{F}}{7}$ Thomas' Hospitals. The role of my committee was to $\stackrel{\Phi}{\varrho}$ devise and introduce a new clinical curriculum for the United Schools. It provided an opportunity to introduce some changes in the curriculum, such as more project $\vec{\circ}$ work, courses in advanced communication skills, $\vec{\omega}$ courses in medical ethics and new methods of $\underset{\sigma}{\omega}$ assessment which demanded of individual departments a statement of their teaching objectives. The Chairmanship of this committee has been an interesting but also harrowing experience, but why should a general practitioner be asked to Chair such a Committee. I am ì not unique. Paul Freeling holds a comparable appoint- ? ment at St. George's and George Irwin and Mal Salkind $N$ have been very influential in this field in Belfast and Sto Bartholomew's.

I would like to take you back to my earlier quotation from Flexner. Flexner introduced a scientific basis fợ $\frac{\sigma}{\sigma}$ medical education which was widely accepted. He recognised also the need for compassion. The big $\infty_{0}^{\circ}$ question was how to marry the two. To quote Flexng again, "Some schools introduced courses in behaviour science, but they proved too didactic. Others, courses 亩 medical ethics, but they proved too moralistic. Of all the measures suggested to solve this problem, the attitudes of members of the faculty are most influential. Clinical $\stackrel{\mathbb{Q}}{\varrho}$ teachers who are respected for their competence but $\overrightarrow{\overrightarrow{0}}$ who also embody compassion in the way they care for 3 their own patients are indispensable".

It seems to me that the general practitioner can provide this mixture of scientific competence and compassion in a unique way, simply because he has a continuing relationship with his patients in a setting of primary care. He can also take an overview of medical $\underset{\varnothing}{\supset}$

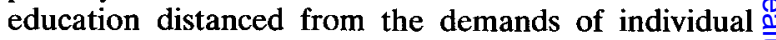
departments and disciplines. In the past we have tended to think of academic general practice as part of the orchestra of medical education and have been obsessed with playing our few bars of the symphony fortissimo to ensure that we are noticed. Maybe we should realise that our natural role is as conductor of the orchestra.

And this brings me back to the reason for my being $\rightarrow$ here tonight - to remember Sir David Bruce. He started out as a humble general practitioner. He joined the army $\mathrm{N}$ because we believe he needed the money and security which the service could offer him and his new bride. I 0 don't suppose he ever saw himself as a great epidemio- $\omega$ logist. He just did the jobs which were presented to him. 
He was however a great naturalist and he had the ability to ask the right questions which is what research is all about, and he had the tenacity to provide the answers. Today we may become nostalgic for the good old days of epidemiology when the researcher, like a sleuth, crept through the savannahs of South Africa or the forest of Uganda looking for mating tsetse flies. We may feel that such exciting prospects are not open to us, but I would suggest to you that the mating habits of the average British soldier are as relevant to the current problems in medical care today as those of the tsetse fly at the turn of the century.

Those of you who are medical officers in the army are presented daily with problems in primary care. You are responsible for defined communities of patients, you have good information about their social and community supports. You have a role which embraces both primary care and occupational health. You have immense opportunities to carry out research. You are not perhaps concerned so much with the microbes and the parasites which fascinated Sir David Bruce, but you are concerned as he was with men and women in their environments. Sir David did not know at the time how his studies would advance knowledge in epidemiology. You do not know how your studies could enhance the understanding of primary care. He simply applied himself to the job in hand, with a very critical mind and supported by a remarkable lady. I am sure he would hope to inspire future generations to a similarly critical approach to the delivery of medical care. You may feel like the double base which makes a rather dull contribution at every second bar. Many of us in academic general practice, and no doubt David Bruce himself, frequently felt like that. You just never know when you will be called upon as I was called upon to conduct the orchestra.

\section{HONORARY CONSULTANTS TO THE ARMY}

Professor P H Fentem, MSC, MB, ChB, MRCP, has been appointed Honorary Consultant in Applied Physiology/Physiology to the Army with effect from 9 January 1989.

Professor W P T James, MA, MD, DSc. FRCP, FRCP (Ed) has been appointed Honorary Consultant in Nutrition to the Army with effect from 18 November 1988. 